\title{
Physical Therapy for Posterior and Horizontal Canal Benign Paroxysmal Positional Vertigo: Long-term Effect and Recurrence: A Systematic Review
}

\author{
Daniele Leite Rodrigues ${ }^{1} \quad$ Alleluia Lima Losno Ledesma ${ }^{2}$ Carlos Augusto Pires de Oliveira ${ }^{3}$ \\ Fayez Bahamad Júnior ${ }^{3}$ \\ ${ }^{1}$ Health Science, Universidade de Brasília, Brasília, DF, Brazil \\ 2 Neonatology Unit, Hospital Regional de Sobradinho, Secretaria de \\ Estado de Saúde do Distrito Federal, Sobradinho, DF, Brazil \\ ${ }^{3}$ Department of Otolaryngology, Medical School, Universidade de \\ Brasília, Brasília, DF, Brazil

\begin{abstract}
Address for correspondence Daniele Leite Rodrigues, Physiotherapist, Ciências da Saúde, Universidade de Brasília, L2 Sul, Quadra 603/4, Lote 23, CEP 70200-640, Brasília, DF, 70910-900, Brazil

(e-mail: daniele.leitejhs@gmail.com).
\end{abstract}

Int Arch Otorhinolaryngol 2018;22:455-459.

\begin{abstract}
Introduction Benign paroxysmal positional vertigo (BPPV) is the most common cause of vertigo, and it is characterized by episodes of vertigo roundabout when the head is moved. A systematic review was performed using the most important scientific databases. This review included studies published in English in the last ten years, performed in adults, with emphasis on the diagnosis and treatment of BPPV.

Objective To investigate the long-term effectiveness of vestibular rehabilitation (VR) in patients with BPPV and the rate of recurrence of symptoms.

Keywords

- benign paroxysmal positional vertigo

- vertigo

- idiopathic recurrent vertigo

- rehabilitation

Data Synthesis A total of 38 studies were identified, of which only 12 met the inclusion criteria. The majority of the studies stated that VR is effective in decreasing the symptoms, with a short-term efficacy of $84.7 \%$, and $89.2 \%$ in the long term in the reviewed studies.

Conclusion Valuable studies show the beneficial effects of the maneuvers for the treatment of BPPV and their long-term effectiveness. This strengthens the conclusion that this treatment is effective in resolving symptoms and decreasing recurrences.
\end{abstract}

\section{Introduction}

Among the peripheral vestibular disorders, benign paroxysmal positional vertigo (BPPV) is the most common. Benign paroxysmal positional vertigo is characterized by episodes of vertigo roundabout when the head is moved. ${ }^{1}$ According to Parnes and Agrawal (2003), $42 \%$ of vertigo cases diagnosed in primary care health services are due to BPPV, affecting especially women and the elderly. Although happening suddenly and unexpectedly, such a sense of vertigo has no progressive characteristic. ${ }^{2}$

Benign paroxysmal positional vertigo can happen through two different mechanisms: the first is known as canalithiasis, in which degenerative debris (otoconia fragments) of the utricle are circulating freely in the endolymph of the semicircular canals of the labyrinth; ${ }^{3}$ the second mechanism, cupulolithiasis, proposes that these same degenerative debris are not circulating in the canals but adhered to the cupula of the posterior canal, making it more sensitive to gravity. ${ }^{4}$

The diagnosis of BPPV is clinical and is done mainly through maneuvers that determine what canal and what type of BPPV patients present. Among them, there is the DixHallpike, described in 1952, which evaluates the anterior and posterior canals and is considered as the gold standard for the diagnosis of BPPV. If it is positive, the person evaluated presents vertigo and nystagmus. ${ }^{5}$ When the affected canal is received

January 29, 2017

accepted

June 4, 2017

published online

August 28, 2017
DOI https://doi.org/

10.1055/s-0037-1604345. ISSN $1809-9777$.
Copyright $(2018$ by Thieme Revinter

Publicações Ltda, Rio de Janeiro, Brazil
License terms

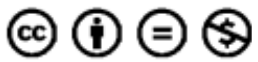


lateral, the best maneuver is the Roll test. The onset of vertigo and nystagmus will also happen in positive cases. ${ }^{6}$

Treatment success depends on identifying and specifying the type of BPPV and canal involved. Formerly, it was believed that only the posterior semicircular canal was involved in this type of dysfunction. However, it is now known that the anterior and lateral semicircular canals may also be involved, although less frequently. $^{7}$

Several forms of therapeutic interventions for this disorder are described in the literature, but there are three basic treatments as follows: canalith repositioning, Brandt-Daroff liberation exercises and Brandt-Daroff habituation exercises, used according to the diagnosis established in the evaluation. ${ }^{8}$

In addition, some patients with BPPV have complaints associated with balance problems, which can last for hours or days after an episode, and feeling of dizziness or flotation. ${ }^{8}$ In such cases, it is necessary to evaluate the patients' postural stability in order to develop a better possible treatment plan. Among the balance tests, there is the Romberg, and a variation called the sensitized Romberg, in which the patient must stand on one foot, with eyes closed on an unstable surface, which distorts the somatosensory feedback. ${ }^{9}$

The goal of this work is to demonstrate that there are benefits to the patients with BPPV treated with vestibular rehabilitation technique, which has been shown to abolish the symptoms of roundabout vertigo and imbalance.

The objective of this systematic review is to investigate the long-term effectiveness of vestibular rehabilitation and the rate of recurrence of symptoms in patients with BPPV.

\section{Review of the Literature}

Searches were conducted in the databases PubMed and LILACS, using the extracted descriptors of Medical Subject Headings (MeSH) that characterized the theme: BPPV AND canalith repositioning maneuver AND benign recurrent vertigo AND vestibular rehabilitation.

The criteria for the selection of the studies were: articles in English; published in the last 10 years; clinical studies in adults with emphasis on the diagnosis and treatment of BPPV. We excluded studies that included patients with neurologic diseases, negative Dix-Hallpike and Roll tests and those with the use of drugs that can inhibit and stimulate vestibular function, or used to compare or complement treatment with vestibular rehabilitation (maneuver of repositioning and liberation).

\section{- Evaluation of studies}

The summaries of 38 articles that fulfilled the search criteria of the survey were reviewed, and 12 studies were included in the study according the selection criteria. - Fig. 1 shows the flow diagram for inclusion.

\section{- Epidemiology data}

This review found 12 studies investigating the effects of vestibular rehabilitation (repositioning maneuvers and canalith liberation) in resolving symptoms of vertigo and nystagmus in patients with BPPV caused by canalithiasis or cupulolithiasis involving the three semicircular canals (-Table 1). In all studies the diagnosis of BPPV is based on the clinical history and the occurrence of nystagmus triggered by the Dix-Hallpike test or Roll test. The sample included 2,335 participants of which 1,414 were women (60.5\%) and 921 were men (39.5\%), and their ages ranged from 20-88 years old.

\section{- Treatment}

Five studies investigated the efficacy of the Epley maneuver; two, the effectiveness of Semont; two compared the Epley and Semont maneuvers to treat posterior canal; one study compared the performance of the Brandt and Epley maneuvers; one study investigated the effects of the Gufoni maneuver and one study assessed the effects of the Epley and Barbecue maneuvers in posterior and lateral canal BPPV (-Table 2). All trials included the positive conversion to a Dix-Hallpike negative test as a measure of outcome and treatment evaluation. Information on the therapeutic maneuvers used for BPPV were provided in all articles.

Articles reporting the effects of the Epley maneuver in the short term stated that $91 \%$ of participants felt improvement of symptoms with one to three therapy maneuvers. In this research, after each Epley or sham maneuver, the Dix-Hallpike test was repeated. If necessary, a therapeutic maneuver (Epley as well as sham maneuver) was repeated up to two times on the same day. Therefore, 95\% of the patients reported complete resolution of symptoms in the long term at the end of follow-up. ${ }^{7}$

When comparing the Epley and Semont maneuvers in the resolution of patients' complaints, the results were similar, with no statistical significance (success rate in treating $48 \%$ of patients with only one Semont maneuver, and $40 \%$ with one Epley maneuver $-p<0.01) .{ }^{10}$ However, Lee et $\mathrm{al}^{11}$ showed that $63.9 \%$ of the sample had an improvement in the symptoms with up to 2 maneuvers, a rate higher than those of the Semont and the sham groups, which, with the same amount of maneuvers, had $37.5 \%$ and $38.7 \%$ of patients with resolution of symptoms respectively. In relation to the recurrence rate, it was lower in the group treated with the Epley maneuver, which had no patient with recurrent vertigo and nystagmus one week after treatment; while there were 3 cases of recurrence with the Semont maneuver. ${ }^{11}$

For the horizontal canal, the intervention with the Gufoni and Barbecue maneuvers proved highly effective, with 92 and $93 \%$ treatment success rates, respectively. ${ }^{12,13}$ Testa et al, in their study, revealed that there is no difference between the Gufoni and the modified Gufoni maneuvers. ${ }^{13}$

About the recurrence of vertigo, $50 \%$ of the analyzed studies assessed the effects of the maneuvers in the long term ( 3 months to 1 year), reaching rates of $89.2 \%$ recovery of patients and decreased relapse. Bruintjes et al and Prokopakis et al had similar results; in the first study, 91\% of treatment success rate (20/22 patients) was observed during the 12 month follow-up, while the group that underwent sham maneuver showed $46 \%(p=0.001)$. In the second study, there was a recurrence rate of $15.5 \%$; it was also observed that the relapse of symptoms was more frequent in the elderly, individuals with vestibular neuropathy or head injury 


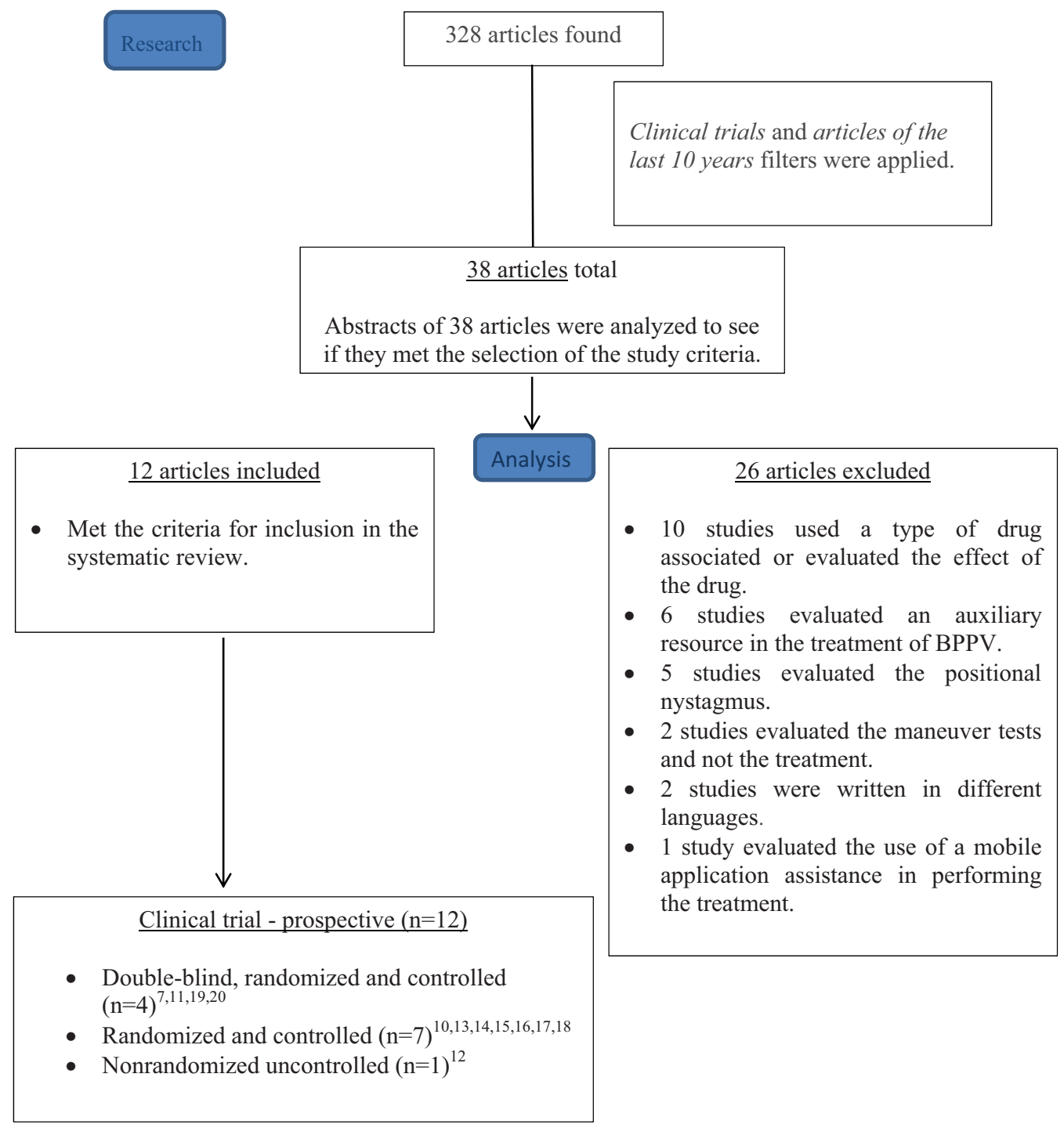

Fig. 1 Diagram showing the selection and type of study used in the review.

$(p<0.001)$. In another follow-up, recurrence was found in 3 $(8.1 \%)$ of the 37 patients in the restriction group and 2 (5.4\%) of the 37 patients in the unrestricted group $(\mathrm{p}>0.05)$. A late recurrence occurred in $5(13.5 \%)$ of the 37 patients in the restriction and non-restriction groups $(\mathrm{p}>0.05) .{ }^{14}$ Tan et al presented a recurrence rate of $6.1 \%$ in the group that used the maneuver, and wanted to emphasize the presence of secondary symptoms, including transient nausea and sweating $(p<0.05)$. Amor-Dorado et al observed a recurrence rate of $35.5 \%$ at 48 months using the Brandt-Daroff exercise and the Epley maneuver to treat the posterior canal $(p=0.62)$. Good long-term results show a decrease in the rate of recurrence with this treatment. $7,12,14-17$

In all these studies, no additional resources were used, such as postural restriction, which had effective influence on the resolution of symptoms or decreased recurrence. ${ }^{14,18-20}$

We can highlight the study by Prokopakis et al, which included 965 patients followed up in the short and long term. The study showed a higher short-term effectiveness, with $92 \%$ success rate and warned that there may be recurrence in 7 to $55 \%$ of the cases long term, especially in the elderly. Vaz et al showed an additional benefit to the treatment by analyzing the effects of the maneuver and also the functional aspects of postural balance in elderly individuals and found that the symptoms of postural instability $(p=0.006)$, nausea, vomiting ( $p=0.021)$ and tinnitus $(p=0.003)$ also improved after the maneuver.

\section{Discussion}

The sample was characterized by individuals aged between 20 and 88 years, and females predominated in this study, representing $60.5 \%$ of the sample. According to Parnes, Agrawal and Atlas, ${ }^{2}$ BPPV is more common in women and seniors over 60 years old, who may present, at this age, other comorbidities.

The investigation of the effects of the various maneuvers was performed to identify the effectiveness and the effects of each one of them in semicircular canals and the mechanisms involved, specifically, because, according to Herdamn et al, accurate diagnosis and choice of appropriate maneuver are crucial to the success of the treatment. ${ }^{7}$ 


\begin{tabular}{|c|c|c|c|c|c|c|c|c|c|c|c|c|}
\hline $\bar{\alpha}$ & 突 & $\stackrel{\circ}{\check{\check{O}}}$ & $\frac{\circ}{\check{\sigma}}$ & ஓ゚ & $\frac{\stackrel{\circ}{r}}{\dot{m}}$ & 1 & 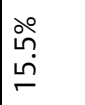 & $\stackrel{\circ}{\stackrel{亠}{~}}$ & $\begin{array}{l}\text { 究 } \\
\text { ஸे }\end{array}$ & 운 & $\frac{\circ}{\check{\sigma}}$ & $\stackrel{\circ}{m}$ \\
\hline 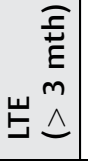 & 1 & 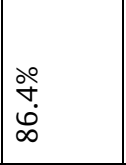 & ڤે & $\frac{\circ}{\sigma}$ & 1 & I & นำ & 1 & $\begin{array}{l}\stackrel{\circ}{\stackrel{\circ}{े}} \\
\text { bे }\end{array}$ & 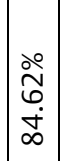 & 1 & 1 \\
\hline $\begin{array}{r}\vec{E} \\
\underline{E} \\
\vec{n} \\
\vec{n}\end{array}$ & $\begin{array}{l}\stackrel{\circ}{\stackrel{\circ}{े}} \\
\text { ஸे }\end{array}$ & $\begin{array}{l}\text { مे } \\
\text { ñ }\end{array}$ & $\begin{array}{l}\text { ڤे } \\
\text { ผู }\end{array}$ & ڤั่ & $\begin{array}{l}\stackrel{0}{0} \\
\infty \\
\infty \\
\varphi\end{array}$ & ஓें & ふે & 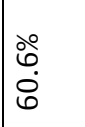 & 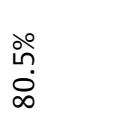 & ळ̊ & 宅 & \begin{tabular}{|l}
$\stackrel{0}{0}$ \\
0 \\
$\infty$ \\
$\infty$ \\
$\infty$
\end{tabular} \\
\hline 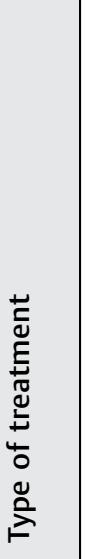 & 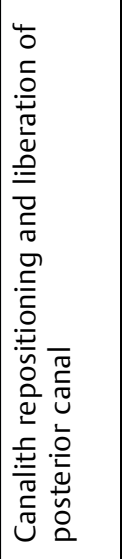 & 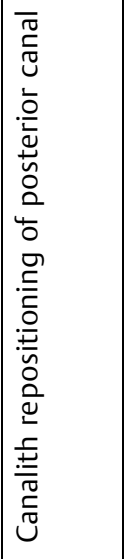 & 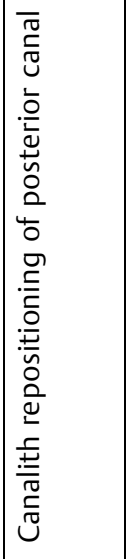 & 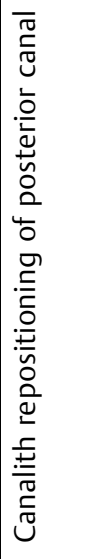 & 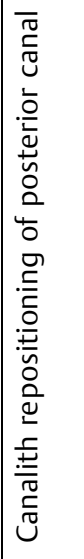 & 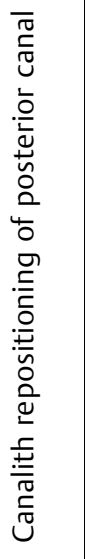 & 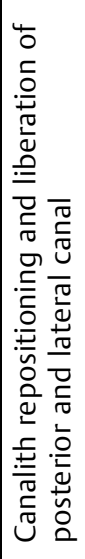 & 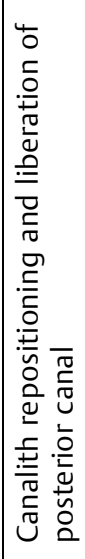 & 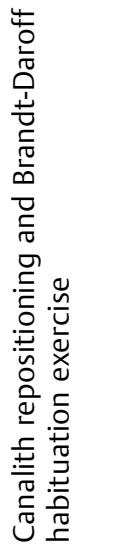 & 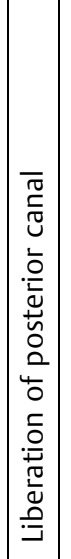 & 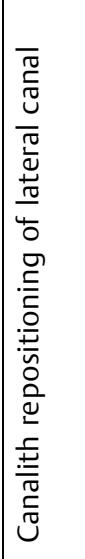 & 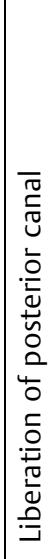 \\
\hline $\begin{array}{l}\frac{\tilde{N}}{n} \\
\frac{0}{0} \\
\frac{0}{n} \\
\sim\end{array}$ & ন & $\stackrel{\infty}{\sim}$ & 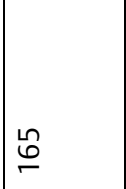 & ষ & ㅇ & $\stackrel{\text { m }}{ }$ & 茫 & $\stackrel{\stackrel{D}{N}}{\stackrel{N}{*}}$ & $\bar{\infty}$ & $\stackrel{\infty}{\sim}$ & $\infty$ & $\stackrel{\sim}{\tilde{m}}$ \\
\hline 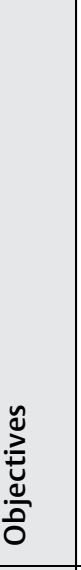 & 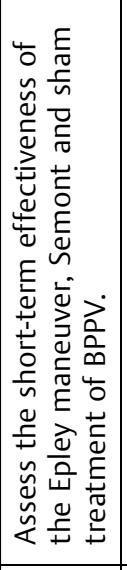 & 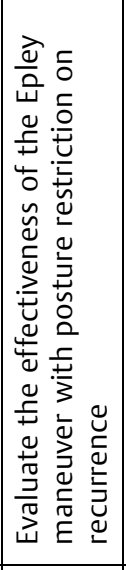 & 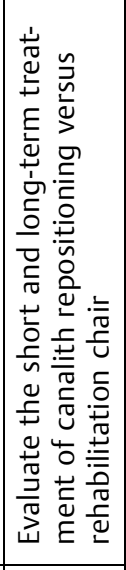 & 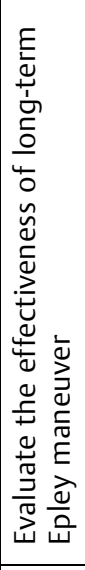 & 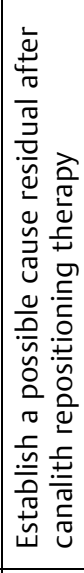 & 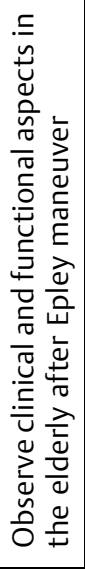 & 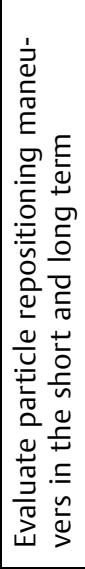 & 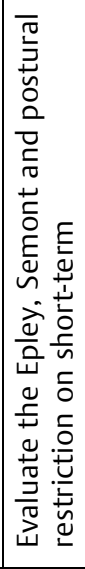 & 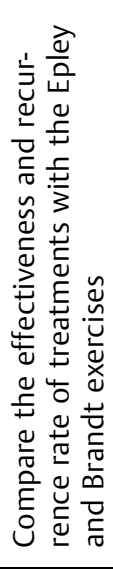 & 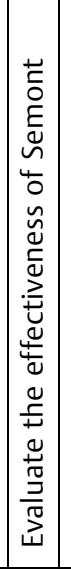 & 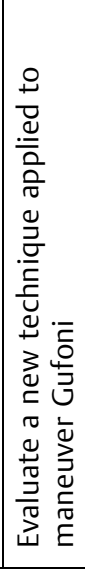 & 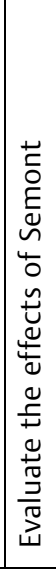 \\
\hline 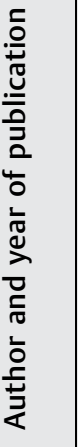 & 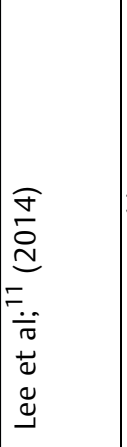 & 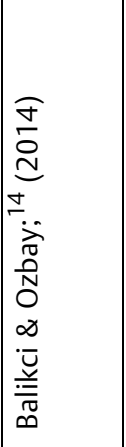 & 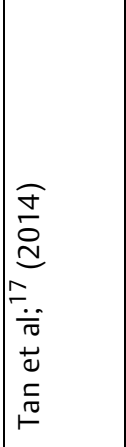 & 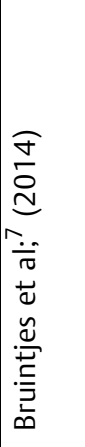 & 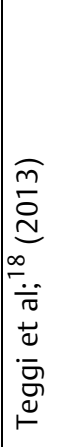 & 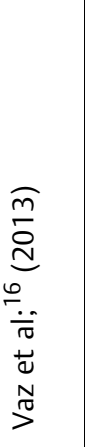 & 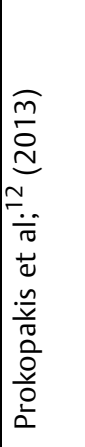 & 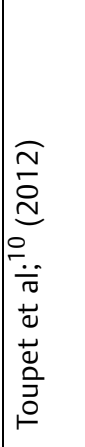 & 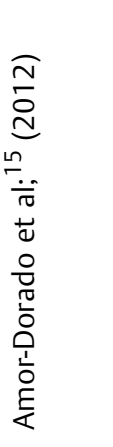 & 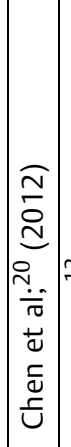 & 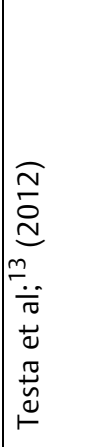 & 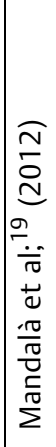 \\
\hline
\end{tabular}


Table 2 Distribution of articles according to strategy

\begin{tabular}{|l|l|l|l|l|l|l|}
\hline & Epley & $\begin{array}{l}\text { Epley and } \\
\text { Semont }\end{array}$ & Semont & $\begin{array}{l}\text { Brandt and } \\
\text { Epley }\end{array}$ & Gufoni & $\begin{array}{l}\text { Barbecue and } \\
\text { Epley }\end{array}$ \\
\hline Strategy & Effectiveness & Comparison & Effectiveness & Comparison & Effectiveness & Effectiveness \\
\hline Number of articles & 5 & 2 & 2 & 1 & 1 & 1 \\
\hline
\end{tabular}

All studies were prospective and were carried from their monitoring of patients and the effects of therapy for a given period. In this way, the articles with a long-term analysis $^{7,12,14,17,20}$ have greater relevance because they could evaluate the success of therapy in a longer period of time, because, although it cannot prevent recurrence, therapy demonstrates good results. Among the studies, 11 of them are randomized, controlled, and only one was not randomized and controlled. In the latter, it was possible to visualize the effect of the therapy in a larger group (965 patients) and different realities, since it was multicenter, showing significant results and success with a small rate of recurrence that was prevalent in the elderly. The fact that the studies are quite homogeneous in many respects makes it possible to compare and combine the results and data found.

The beneficial effects of the maneuvers were significant in the treatment of BPPV in all studies, and the reduction of the rate of recurrence was identified in the studies that accompanied the long-term efficacy of the treatment and recurrence rate. What proves the importance of using this treatment. $^{11,16}$

\section{Final Comments}

The benefits of vestibular rehabilitation in the treatment of patients with BPPV are already known from the literature, but it is also important to highlight their short and long-term effects. Moreover, it is an effective, reliable and non-invasive therapeutic approach, which leads to consider it as an important treatment option.

In this review, we could demonstrate the beneficial results of the maneuvers for the treatment of BPPV and their longterm effects. This strengthens the conclusion that this treatment is effective in resolving symptoms.

\section{References}

1 Brandt T, Daroff RB. Physical therapy for benign paroxysmal positional vertigo. Arch Otolaryngol 1980;106(08):484-485

2 Parnes LS, Agrawal SK, Atlas J. Diagnosis and management of benign paroxysmal positional vertigo (BPPV). CMAJ 2003; 169(07):681-693

3 Hall SF, Ruby RR, McClure JA. The mechanics of benign paroxysmal vertigo. J Otolaryngol 1979;8(02):151-158

4 Schuknecht HF. Cupulolithiasis. Arch Otolaryngol 1969;90(06): 765-778

5 Silva AL, Marinho MR, Gouveia FM, Silva JG, Ferreira AdeS, Cal R. Benign Paroxysmal Positional Vertigo: comparison of two recent international guidelines. Rev Bras Otorrinolaringol (Engl Ed) 2011;77(02):191-200
6 Teixeira LJ, Machado JNP. Manobras para o tratamento da vertigem posicional paroxística benigna: revisão sistemática da literatura. Rev Bras Otorrinolaringol (Engl Ed) 2006;72:130-139

7 Bruintjes TD, Companjen J, van der Zaag-Loonen HJ, van Benthem PP. A randomised sham-controlled trial to assess the long-term effect of the Epley manoeuvre for treatment of posterior canal benign paroxysmal positional vertigo. Clin Otolaryngol 2014; 39(01):39-44

8 Burlamaqui JC, de Campos CAH, Mesquita Neto O. Manobra de Epley para Vertigem Postural Paroxística Benigna: revisão sistemática. Acta Otorrinolaringol 2006;24(01):38:45

9 Herdman SJ, Tusa RJ. Evaluation and Management of the patients with BPPV. In: Herdman SJ. Vestibular Rehabilitation. Philadelphia: Contemporary Perspectives in Rehabilitation; 2002;3:493-497

10 Toupet M, Ferrary E, Bozorg Grayeli A. Effect of repositioning maneuver type and postmaneuver restrictions on vertigo and dizziness in benign positional paroxysmal vertigo. -. Sci World J 2012;162:123-126

11 Lee JD, Shim DB, Park HJ, et al. A multicenter randomized doubleblind study: comparison of the Epley, Semont, and sham maneuvers for the treatment of posterior canal benign paroxysmal positional vertigo. Audiol Neurootol 2014;19(05):336-341

12 Prokopakis E, Vlastos IM, Tsagournisakis M, Christodoulou P, Kawauchi H, Velegrakis G. Canalith repositioning procedures among 965 patients with benign paroxysmal positional vertigo. Audiol Neurootol 2013;18(02):83-88

13 Testa D, Castaldo G, De Santis C, Trusio A, Motta G. Treatment of horizontal canal benign paroxysmal positional vertigo: a new rehabilitation technique. -. Sci World J 2012;160:475-478

14 Balikci HH, Ozbay I. Effects of postural restriction after modified Epley maneuver on recurrence of benign paroxysmal positional vertigo. Auris Nasus Larynx 2014;41(05):428-431

15 Amor-Dorado JC, Barreira-Fernández MP, Aran-Gonzalez I, Casariego-Vales E, Llorca J, González-Gay MA. Particle repositioning maneuver versus Brandt-Daroff exercise for treatment of unilateral idiopathic BPPV of the posterior semicircular canal: a randomized prospective clinical trial with short- and long-term outcome. Otol Neurotol 2012;33(08):1401-1407

16 Vaz DP, Gazzola JM, Lança SM, Dorigueto RS, Kasse CA. Clinical and functional aspects of body balance in elderly subjects with benign paroxysmal positional vertigo. Rev Bras Otorrinolaringol (Engl Ed) 2013;79(02):150-157

17 Tan J, Yu D, Feng Y, et al. Comparative study of the efficacy of the canalith repositioning procedure versus the vertigo treatment and rehabilitation chair. Acta Otolaryngol 2014;134(07):704-708

18 Teggi R, Quaglieri S, Gatti O, Benazzo M, Bussi M. Residual dizziness after successful repositioning maneuvers for idiopathic benign paroxysmal positional vertigo. ORL J Otorhinolaryngol Relat Spec 2013;75(02):74-81

19 Mandalà M, Santoro GP, Asprella Libonati G, et al. Double-blind randomized trial on short-term efficacy of the Semont maneuver for the treatment of posterior canal benign paroxysmal positional vertigo. J Neurol 2012;259(05):882-885

20 Chen Y, Zhuang J, Zhang L, et al. Short-term efficacy of Semont maneuver for benign paroxysmal positional vertigo: a doubleblind randomized trial. Otol Neurotol 2012;33(07):1127-1130 